\title{
Association Between NR4A2 Gene Polymorphism and Depressive Symptoms and Antidepressant Effect
}

\author{
Xiaotong Song ${ }^{1,2}$ \\ Ning Sun ${ }^{1-3}$ \\ Aixia Zhang ${ }^{1-3}$ \\ Lei Lei ${ }^{1}$ \\ Xinrong $\mathrm{Li}^{\prime}$ \\ Zhifen Liu ${ }^{\mathrm{I}-3}$ \\ Yanfang Wang' \\ Chunxia Yang ${ }^{1-3}$ \\ Kerang Zhang' \\ 'Department of Psychiatry, First Hospital \\ of Shanxi Medical University, Taiyuan, \\ People's Republic of China; ${ }^{2}$ Laboratory \\ of Artificial Intelligence Assisted \\ Diagnosis and Treatment for Mental \\ Disorder, First Hospital of Shanxi Medical \\ University, Taiyuan, People's Republic of \\ China; ${ }^{3}$ Department of Mental Health, \\ Shanxi Medical University, Taiyuan, \\ People's Republic of China
}

\begin{abstract}
Objective: Although the pathogenesis of major depressive disorder (MDD) is still unclear, studies have shown that the dopaminergic system of depressed patients is defective, and that NR4A2 is an important transcription factor affecting the development and maintenance of dopaminergic neurons. As such, NR4A2 levels affected by NR4A2 single nucleotide polymorphisms (SNPs) may be associated with MDD. This study examined whether NR4A2 SNPs are associated with depressive symptoms and antidepressant efficacy.

Methods: A total of 441 patients with first-episode depression were enrolled in this study. We analysed three SNPs of NR4A2, using the 17-item Hamilton Depression Rating Scale (HAM-D) and its four factors to obtain scores at baseline and at the end of 6 weeks. UNPHASED software was employed for quantitative character analysis, and SPSS software was adopted for antidepressant efficacy analysis.

Results: Patients with rs12803-A exhibited higher scores of retardation symptoms. Patients with the rs834834-C allele and rs834834-CC genotype had higher retardation symptom scores. Patients with rs3769340 exhibited greater antidepressant efficacy.

Conclusion: NR4A2 gene polymorphisms are associated with retardation symptoms, somatic symptoms (gastro-intestinal), anxiety-based somatic symptoms, insight, and weight loss in patients with MDD. Additionally, rs3769340 may be a predictor of antidepressant efficacy in patients with major depressive disorder.
\end{abstract}

Keywords: major depressive disorder, NR4A2, single nucleotide polymorphism, antidepressant treatment

\section{Introduction}

Major depressive disorder (MDD) is a chronic illness that affects an individual's mental, emotional and physical health. It is characterized by low mood, absence vitality, sadness, insomnia, etc. Nevertheless, its etiology and pathogenesis remain indistinct. Studies show that the heritability of depressive disorder is $38 \%$. However, the neural mechanism of how risk loci contribute to MDD remains unclear. ${ }^{1}$ A growing body of evidence suggests that dopamine (DA) can play a role in the pathophysiology of MDD and the efficacy of antidepressants. Thus, genetic variants involved in regulating endogenous dopaminergic neurotransmission may have a significant role in the pathophysiology of MDD. Although the results are not consistent, several studies have identified a number of genetic variants associated with dopamine, including the catechol-O-methyltransferase (COMT) gene, monoamine oxidase A (MAOA) gene, dopamine D2 receptor (DRD2) and dopamine transporter (DAT) gene, which are strongly associated with depressive disorder and antidepressant response. ${ }^{2}$ Taken together, these
Correspondence: Chunxia Yang; Kerang Zhang

Department of Psychiatry, First Hospital of Shanxi Medical University, Taiyuan,

People's Republic of China

Email ychunxia2000@I63.com;

atomsxmu@vip.I63.com 
findings suggest that multiple genetic effects of the DA pathway play a key role in the pathophysiology of depressive disorders. ${ }^{3}$ Dopaminergic activity is complicated and regulated by a variety of brain structures, including the basolateral amygdala and the ventral inferior seat of the hippocampus. Although basic and clinical studies have shown defects in the dopaminergic system in depressed patients, these defects may be rooted in disorders in the regulation of the afferent circuits. ${ }^{4}$ NR4A2 is a nuclear receptor and transcription factor with unique physiological characteristics. The NR4A2 gene is related to neural development or synaptic transmission, especially dopamine neurotransmission, and can also affect the development and maintenance of midbrain dopaminergic neurons. It is widely expressed in the nucleus of the central nervous system and is considered to be an important regulator of the differentiation, survival, and maintenance of dopaminergic neurons. The expression of NR4A2 in microglia and astrocytes inhibited the expression of proinflammatory mediators. Thus, it protects against inflammatory-mediated dopamine neuronal death. ${ }^{5-7}$

The expression of NURR1 mRNA in adult mice was detected by in situ hybridization. After $30 \mathrm{~min}$ and $3 \mathrm{~h}$ of forced swimming experiment, the expression of NURR1 mRNA was increased not only in the whole cerebral cortex but also in the dopamine cell body region. NURR1 mRNA levels decreased 3 hours after the forced swimming session compared to 30 minutes after the forced swimming session, and dopamine levels in the prefrontal lobe and midbrain decreased. The results suggest that the increased expression of NR4A2 may be a compensatory mechanism to counteract changes in forebrain dopamine transmission, particularly in response to acute stress. ${ }^{8}$ In situ hybridization guided laser capture microdissection was used to take brain tissue samples from patients with depression and healthy subjects at autopsy. The extracted RNA gene expression profiles showed down-regulation of transcription regulator NR4A2, early growth factor 1 and its downstream targets in patients with MDD. ${ }^{9}$

Homozygous NURR1 knockout mice (NURR1 -/-) showed selective dysplasia of midbrain dopamine neurons and died within 1 day of birth. Although heterozygous NURR1 mice (NURR1 +/-) showed normal performance, they showed significantly reduced dopamine levels in the midbrain, prefrontal cortex, striatum, and nucleus accumbens;Increased motor response to stress. ${ }^{10,11}$ Injections of 6-hydroxydopamine into the midbrain and striatum lead to depletion of dopamine and increase in the number of cells expressing NURR1 mRNA and protein in the substantia nigra (dense body and reticulum). ${ }^{12}$ Duration of midbrain dopamine neurons leads to corresponding loss of NURR1 mRNA in the midbrain. ${ }^{13}$ There are few studies on the association between the NR4A2 gene and major depressive disorder, and the current research mainly focuses on the relationship between the NR4A2 gene and neuropsychiatric diseases, such as schizophrenia (SCZ), bipolar disorder (BPD), and Parkinson's disease. ${ }^{14-20}$

At present, the relationship between antidepressant efficacy and NR4A2 is unclear. At the same time, there is little research on the effects of NR4A2 and antidepressants. Therefore, in the present study, we aimed to more accurately describe the associations between the NR4A2 gene and depressive symptoms/antidepressant efficacy in patients with major depressive disorder.

\section{Subjects and Methods Subjects}

with an average age of $34.65 \pm 12.04$ years, HAM-D17 total score of 22.04 \pm 4.01 , who had their first episode of MDD at the First Hospital of Shanxi Medical University. Patients were selected by at least 2 psychiatrists with strict training and rich clinical experience according to the diagnostic criteria of MDD in the Diagnostic and Statistical Manual of Mental Disorders, Fourth Edition IV). ${ }^{21}$ Inclusion criteria were as follows: 1) Han nationality; $18 \leq$ age $\leq 65 ; 2$ ) Compliance with the diagnostic criteria of depression disorder in the Diagnostic and Statistical Manual of Mental Disorders, Fourth edition (DSM-IV); 3) 17-item Hamilton Scale (HAM-D17) score $\geq 17$. Exclusion criteria were as follows: 1) Patients with bipolar disorder, schizophrenia and other mental disorders; 2) Diseases of the nervous system or other diseases that may affect the structure or function of the brain; 3) Patients with genetic diseases; 4) Gastrointestinal diseases, hepatobiliary diseases, renal insufficiency and other diseases that affect the normal absorption, metabolism, distribution, and excretion of antidepressants. All patients signed informed consent. This research scheme was approved by the Institutional Review Board of the First Hospital of Shanxi Medical University (20091217) and this study was conducted in accordance with the Declaration of Helsinki. HAM-D 17 items and its four factors were adopted to assess symptoms and severity. Four of the factors were anxiety/physical symptoms (items 10,11, 12, 13, 15 and 17), insomnia symptoms (items 4, 5 and 6), loss of weight symptoms 
(items 16), and retardation symptoms (items 1, 7, 8, and 14).

\section{Evaluation of Antidepressant Use and Efficacy}

Selective serotonin reuptake inhibitors (SSRIs) were used to treat all patients, namely, fluoxetine, paroxetine, sertraline, and escitalopram, with minimum therapeutic doses of $20 \mathrm{mg} / \mathrm{d}, 20 \mathrm{mg} / \mathrm{d}, 50 \mathrm{mg} / \mathrm{d}$, and $10 \mathrm{mg} / \mathrm{d}$, respectively. Increase the dose slowly and reach the therapeutic dose within 2 weeks. Low doses of benzodiazepines may be adopted in patients with sleep disorders during treatment. Doses can be adjusted during treatment according to the patient's clinical symptoms.

A total of 222 patients completed six weeks of treatment. If the total score of HAM-D17 $\leq 7$ at 6 weeks, it was rated as remission group; otherwise, it was rated as nonremission group. If the total score reduction rate of HAMD17 at 6 weeks is $\geq 50 \%$, it will be assessed as an effective group; otherwise, it will be assessed as an ineffective group.

\section{Methods}

\section{Genotyping and PCR}

Haploview software was used to screen the genetic loci associated with NR4A2 levels; three Tag SNPs (rs12803, rs3769340 and rs834834) were selected from the Han Chinese of Beijing (CHB) in the NCBI database. SNPs rs12803, rs3769340, and rs834834 were tested for association with variations in NR4A2 concentration. SNP rs12803 and occurred in the $3^{\prime}$ untranslated region, SNP rs3769340 and rs834834 occurred in the intron1. DNA was extracted from a blood sample drawn from the peripheral blood. Three genotypes loci were identified using polymerase chain reaction (PCR) and sequencing technology. The primers were designed using Primer 5.0 software (PREMIER Biosoft Inc., Palo Alto, CA, USA). Primer homology was compared by entering multiple pairs of primers into the BLAST database of the National Library of the United States. The primers with the least homology and with suitable Tm values were selected as PCR reaction primers. For genotyping the NR4A2 gene rs12803, forward primer 5' ACG TTG GAT GCT GAA CTG CAA CAA CCA AGC-3' and reverse primer 5' ACG TTG GAT GGT TTG TTG TTC AGA AGA AAG-3' were used. For rs3769340, forward primer 5' ACG TTG GAT GTC TCG CTC TGA TAC ATT CGC-3' and reverse primer 5' ACG
TTG GAT GTA GCG TGT CCT GTT ACT AAG-3' were used. Finally, for rs834834, forward primer 5' ACG TTG GAT GCA ATT AGG GAT GGT GCT ACG-3' and reverse primer 5' ACG TTG GAT GGG ATG GCA CTG TAT TTA GTC-3' were used.

\section{Statistical Analysis}

The Hardy-Weinberg equilibrium of the genotype distribution of SNPs was tested by the chi-square test of goodness of fit. UNPHASED software was adopted to analyze the linkage disequilibrium. Associations between the total and cluster score of HAMD-17 and allelic and genotype were analyzed using UNPHASED. In case of $\mathrm{P}<0.05$, 10,000 permutation tests were performed to correct for multiple tests. The association between genotypes and antidepressant efficacy expressed as a dichotomous variable was analyzed with chi-square tests using SPSS ver. 23.0 (IBM Corporation, Armonk, NY, USA). Genotype frequency $<0.01$ was excluded. The statistical significance level was $* P<0.05$.

\section{Result}

\section{General Information}

Three NR4A2 SNPs exhibited Hardy-Weinberg equilibrium: $\operatorname{rs} 12803(\mathrm{P}=0.771), \operatorname{rs} 3769340(\mathrm{P}=0.992)$, and rs834834 $(\mathrm{P}=0.234)$. The genotypic distributions of the rs1927911, rs11536889, and rs7873784 polymorphisms were in Hardy-Weinberg equilibrium. Linkage disequilibrium (LD) values for $\mathrm{r}^{2}$ and $\mathrm{D}$ ' were as follows: rs12803rs3769340 $\left(\mathrm{r}^{2}=0.025, \mathrm{D}^{\prime}=-1\right)$; $\mathrm{rs} 12803-\mathrm{rs} 834834\left(\mathrm{r}^{2}=\right.$ $\left.0.281, D^{\prime}=-1\right)$; rs834834-rs3769340 $\left(r^{2}=0.089, D^{\prime}=-1\right)$.

\section{Depressive Symptoms and NR4A2 Gene Polymorphisms}

As shown in Tables 1-4, an association between the HAM-D total and clusters scores and NR4A2 alleles and genotypes was observed. Among the HAM-D clusters, we observed that Retardation: psychomotor was associated with rs 12803 alleles $(\chi 2=4.289$, corrected $P=0.036$ ). Somatic symptoms (gastro-intestinal) were significantly associated with rs 12803 alleles $(\chi 2=3.984$, corrected $P=0.048)$. Insight was significantly associated with rs 12803 alleles $(\chi 2=4.496$, corrected $P=0.040)$. Somatic anxiety symptoms were significantly associated with rs12803 genotype $(\chi 2=4.594$, corrected $P=0.036)$. Retardation symptoms were significantly associated with rs 12803 alleles $(\chi 2=6.440$, corrected $P=0.012)$. Patients 


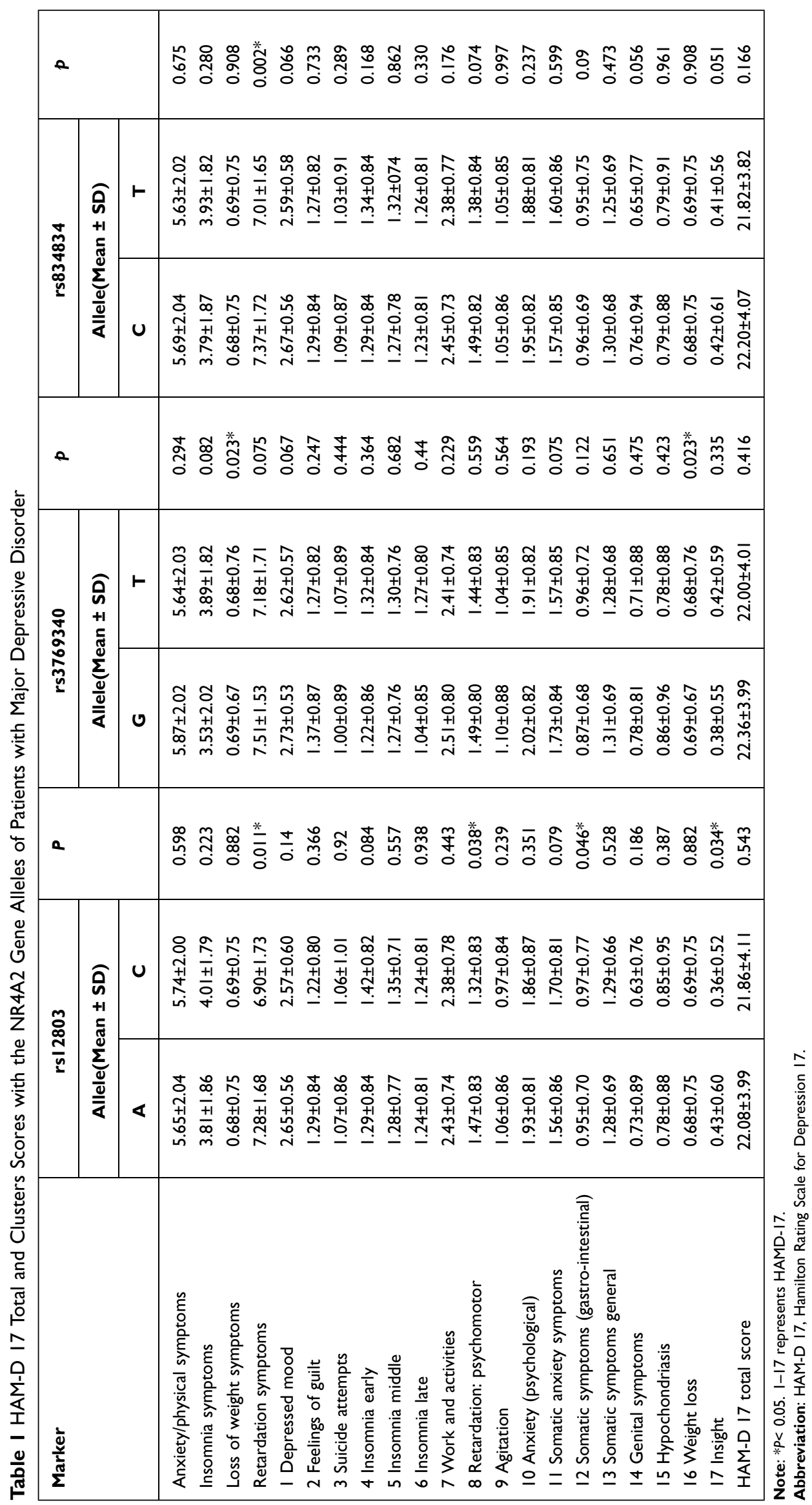




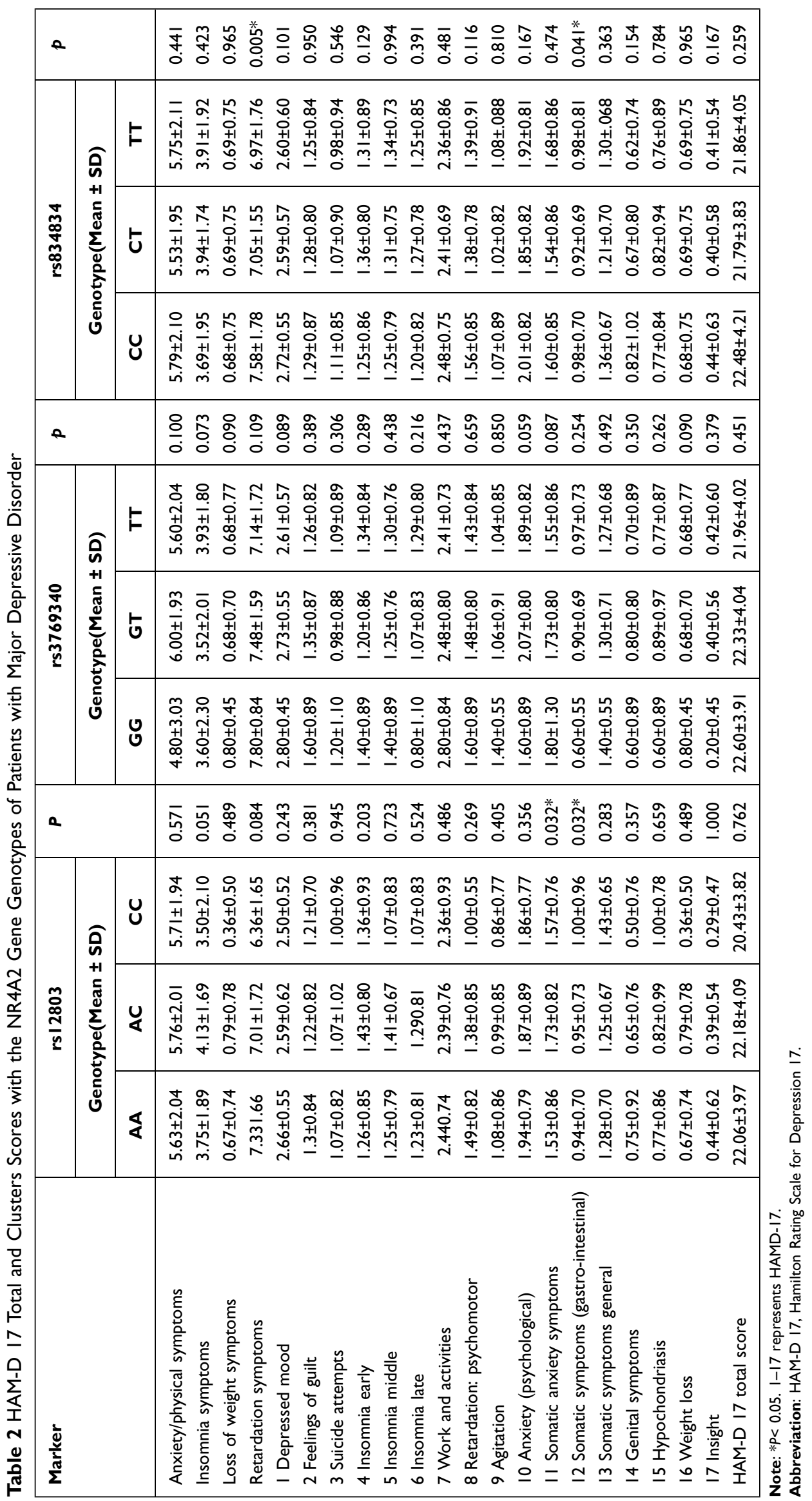


Table 3 HAM-D 17 Total and Clusters Scores and the NR4A2 Gene Alleles of Patients with Major Depressive Disorder

\begin{tabular}{|c|c|c|c|c|c|c|}
\hline \multirow[t]{2}{*}{ SNP } & \multirow[t]{2}{*}{ HAM-D Category } & \multicolumn{2}{|c|}{ Allele } & \multirow[t]{3}{*}{$\chi^{2}$} & \multirow[t]{3}{*}{$P$-value } & \multirow{3}{*}{$\begin{array}{l}\text { Adjusted } \\
P_{\text {-value }}\end{array}$} \\
\hline & & \multicolumn{2}{|c|}{ Mean Score } & & & \\
\hline \multirow[t]{5}{*}{ rs 12803} & & A (730) & $C(152)$ & & & \\
\hline & Retardation: psychomotor & 1.47 & 1.32 & 4.289 & 0.038 & 0.036 \\
\hline & Somatic symptoms (gastro-intestinal) & 0.95 & 0.97 & 3.984 & 0.046 & 0.048 \\
\hline & Insight & 0.43 & 0.36 & 4.496 & 0.034 & 0.040 \\
\hline & Retardation symptoms & 7.28 & 6.90 & 6.440 & 0.011 & 0.012 \\
\hline \multirow[t]{2}{*}{ rs3769340 } & & G (94) & $\mathrm{T}(788)$ & & & \\
\hline & Weight loss & 0.69 & 0.68 & 5.206 & 0.023 & 0.026 \\
\hline \multirow[t]{2}{*}{ rs834834 } & & $C(505)$ & $\mathrm{T}(377)$ & & & \\
\hline & Retardation symptoms & 7.37 & 7.01 & 9.515 & 0.002 & 0.003 \\
\hline
\end{tabular}

Notes: ${ }^{\text {T}}$ The adjusted $P$-value after 10,000 permutation tests. The value in parenthesis represents the number of patients with $A, C, G$, and $T$ alleles.

Table 4 HAM-D 17 Total and Clusters Scores and the NR4A2 Genotypes of Patients with Major Depressive Disorder

\begin{tabular}{|c|c|c|c|c|c|c|c|}
\hline \multirow[t]{2}{*}{ SNP } & \multirow[t]{2}{*}{ HAM-D Category } & \multicolumn{3}{|c|}{ Genotype } & \multirow[t]{3}{*}{$\chi^{2}$} & \multirow[t]{3}{*}{$P$-value } & \multirow{3}{*}{$\begin{array}{c}\text { Adjusted } \\
\text {-value }^{\mathrm{a}}\end{array}$} \\
\hline & & \multicolumn{3}{|c|}{ Mean Score } & & & \\
\hline \multirow[t]{2}{*}{ rs $\mid 2803$} & & AA (303) & $A C(124)$ & CC (14) & & & \\
\hline & Somatic anxiety symptoms & 1.53 & 1.73 & 1.57 & 4.594 & 0.032 & 0.036 \\
\hline \multirow[t]{3}{*}{ rs834834 } & & $C C(151)$ & CT (203) & TT (87) & & & \\
\hline & Somatic symptoms (gastro-intestinal) & 0.98 & 0.92 & 0.98 & 6.386 & 0.041 & 0.043 \\
\hline & Retardation symptoms & 7.58 & 7.05 & 6.97 & 10.740 & 0.005 & 0.005 \\
\hline
\end{tabular}

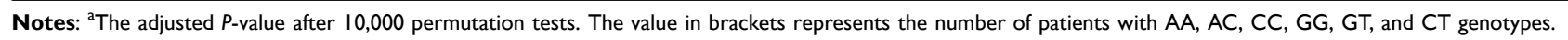

with the rs12803-A allele had significantly higher retardation symptoms scores as compared to patients with the rs12803-C allele.

Moreover, Weight loss was significantly associated with rs3769340 alleles $(\chi 2=5.206$, corrected $P=0.026)$.

In patients with rs834834, somatic symptoms (gastrointestinal) were significantly associated with genotype $(\chi 2=6.386$, corrected $P=0.043)$. Retardation symptoms were significantly associated with rs834834 alleles $(\chi 2=9.515$, corrected $P=0.003)$ and genotype $(\chi 2=10.740$, corrected $P=0.005$ ). Patients with the rs834834-C allele and rs834834$\mathrm{C} / \mathrm{C}$ had significantly higher Retardation symptoms scores than those with rs834834-C/T or $\mathrm{T} / \mathrm{T}$ genotypes or the rs834834-T allele, respectively.

In addition to the above, there were no significant differences in other HAM-D cluster scores with alleles or genotypes for rs12803, rs3769340, or rs834834 after permutation testing.

\section{NR4A2 Gene Polymorphisms and Antidepressant Efficacy}

As shown in Tables 5-7, the distribution of rs3769340 was statistically different between the effective group and the ineffective group $(\chi 2=1.260, P=0.042)$. There was no significant difference in the distribution of SNP genotypes between the remission group and the non-remission group. On this basis, stratified analysis was conducted by age, gender and symptom severity, etc., and there was no statistical difference.

\section{Discussion}

In our study, we investigated the association between NR4A2 gene polymorphisms and depressive symptoms and antidepressant efficacy. The results revealed that NR4A2 gene polymorphisms were associated with partial depressive symptoms, and NR4A2 rs3769340 was associated with the efficacy of antidepressant. 
Table 5 The NR4A2rs 12803 Genotypes and Antidepressant Efficacy in Patients with Major Depressive Disorder

\begin{tabular}{|c|c|c|c|c|c|c|}
\hline \multicolumn{2}{|l|}{ Outcome Measure } & \multicolumn{2}{|c|}{ Genotype } & \multirow[t]{2}{*}{ Total } & \multirow[t]{2}{*}{$\chi^{2}$} & \multirow[t]{2}{*}{$\mathbf{P}$} \\
\hline & & AA & $\mathrm{AC} / \mathrm{CC}$ & & & \\
\hline \multirow[t]{3}{*}{ Remission and non-remission } & Remission & 97 & 37 & 134 & \multirow[t]{3}{*}{1.450} & \multirow[t]{3}{*}{0.229} \\
\hline & Non-remission & 57 & 31 & 88 & & \\
\hline & Total & 154 & 68 & 222 & & \\
\hline \multirow[t]{3}{*}{ Effective and ineffective } & Effective & 128 & 57 & 185 & \multirow[t]{3}{*}{0.017} & \multirow[t]{3}{*}{0.896} \\
\hline & Ineffective & 26 & 11 & 37 & & \\
\hline & Total & 154 & 68 & 222 & & \\
\hline
\end{tabular}

Table 6 The NR4A2rs 3769340 Genotypes and Antidepressant Efficacy in Patients with Major Depressive Disorder

\begin{tabular}{|c|c|c|c|c|c|c|}
\hline \multicolumn{2}{|l|}{ Outcome Measure } & \multicolumn{2}{|c|}{ Genotype } & \multirow[t]{2}{*}{ Total } & \multirow[t]{2}{*}{$\chi^{2}$} & \multirow[t]{2}{*}{$P$} \\
\hline & & GG/GT & $\mathbf{T T}$ & & & \\
\hline \multirow[t]{3}{*}{ Remission and non-remission } & Remission & 21 & 113 & 134 & \multirow[t]{3}{*}{1.260} & \multirow[t]{3}{*}{0.262} \\
\hline & Non-remission & 19 & 69 & 88 & & \\
\hline & Total & 40 & 182 & 222 & & \\
\hline \multirow[t]{3}{*}{ Effective and ineffective } & Effective & 29 & 156 & 185 & \multirow[t]{3}{*}{4.123} & \multirow[t]{3}{*}{0.042} \\
\hline & Ineffective & 11 & 26 & 37 & & \\
\hline & Total & 40 & 182 & 222 & & \\
\hline
\end{tabular}

Table 7 The NR4A2rs 834834 Genotypes and Antidepressant Efficacy in Patients with Major Depressive Disorder

\begin{tabular}{|c|c|c|c|c|c|c|c|}
\hline \multicolumn{2}{|l|}{ Outcome Measure } & \multicolumn{3}{|c|}{ Genotype } & \multirow[t]{2}{*}{ Total } & \multirow[t]{2}{*}{$\chi^{2}$} & \multirow[t]{2}{*}{$\mathbf{P}$} \\
\hline & & CC & CT & TT & & & \\
\hline \multirow[t]{3}{*}{ Remission and non-remission } & Remission & 45 & 62 & 27 & 134 & \multirow[t]{3}{*}{0.010} & \multirow[t]{3}{*}{0.995} \\
\hline & Non-remission & 29 & $4 I$ & 18 & 88 & & \\
\hline & Total & 74 & 103 & 45 & 222 & & \\
\hline \multirow[t]{3}{*}{ Effective and ineffective } & Effective & 58 & 89 & 38 & 185 & \multirow[t]{3}{*}{2.049} & \multirow[t]{3}{*}{0.359} \\
\hline & Ineffective & 16 & 14 & 7 & 37 & & \\
\hline & Total & 74 & 103 & 45 & 222 & & \\
\hline
\end{tabular}

First, we found that the rs 12803 gene polymorphism was significantly associated with retardation: psychomotor in patients with MDD. Individuals with the rs12803-A allele had significantly higher retardation symptoms scores. At the same time, there was also a significant association between the rs 834834 gene polymorphism and retardation symptoms in patients with MDD.
Besides, individuals with the rs834834-C allele andrs834834-C/C genotype had significantly higher retardation symptoms scores. Studies have shown that retardation: psychomotor is an important aspect of MDD. ${ }^{22}$ The retardation: psychomotor includes impaired cognitive function, reduced motor activity, and impaired cognitive function. It often occurs in people with MDD and 
psychotic symptoms. The biological link is an abnormality in the brain's basal ganglia and dopamine energy pathways. ${ }^{23}$ Savitz et $\mathrm{al}^{24}$ observed that the expression of neuroprotective NR4A2 was positively correlated with the volume of hippocampal gray matter. NR4A2 is associated with various forms of dementia or age-related pathology. Depression is not only a precursor of Alzheimer's disease but early-onset, primary mood disorders also increase the risk of Alzheimer's disease in older people. Saczynski et $\mathrm{al}^{25}$ followed participants for 17 years, and the results showed that the risk of developing Alzheimer's disease and other dementias later in life increased by more than $50 \%$ in depressed subjects. Leonard believed that inflammation-induced neuropathological changes related to MDD could induce neurodegenerative changes such as Alzheimer's disease. ${ }^{26}$ Therefore, it is necessary to study further the NR4A2 gene for dopaminergic neuron differentiation, instead of only the role of NR4A2 in MDD and psychomotor retardation.

In this study, the rs12803 gene polymorphism and the rs834834 gene polymorphism were associated with somatic symptoms (gastro-intestinal) in patients with MDD. There is evidence of bidirectional communication between the gut and the brain, including neurologic, metabolic, endocrine and inflammatory mediators. ${ }^{27}$ The MDD may be associated with excessive inflammation and dysregulation of the gut-brain axis. Excess inflammatory response is associated with brain changes (depressive symptoms, fatigue, difficulty sleeping) and worsening gastrointestinal symptoms, which can be exacerbated by psychological distress. ${ }^{28}$ Studies have shown differences in the composition of the gut microbiota between people diagnosed with MDD and healthy people. ${ }^{29}$ NR4A2 transactivates Forkhead box protein (Foxp3), which is a marker of specific expression in regulatory $\mathrm{T}$ (Treg) cells and plays a key role in differentiation, maintenance, and function of Treg cells. NR4A2 in T lymphocytes is the key to inducing Treg cells under physiological and pathological conditions. High density Foxp3(+) Treg cells were significantly associated with gastrointestinal inflammation and disease progression. Abnormal expression of NR4A2 can trigger various inflammatory signaling pathways, such as cAMP/PKA and NF- $\mathrm{kB}$, and promote the occurrence and development of gastrointestinal inflammation and tumor. ${ }^{30}$ These results indicate that NR4A2 gene may play an important role in the occurrence of gastrointestinal inflammation and tumors, and the role of NR4A2 in the gastrointestinal symptoms of patients with depression requires further study on the relationship and role of NR4A2related transcription factors, inflammatory factors and depression.

The rs12803 gene polymorphism was associated with somatic anxiety symptoms in patients with MDD. Epidemiological studies have shown that MDD and anxiety disorders occur in up to $25 \%$ of patients. About $85 \%$ of patients with MDD have significant anxiety, and $90 \%$ of patients with anxiety disorder have MDD. ${ }^{31}$ The study by Le-Niculescu et al provided evidence for the involvement of NR4A2 gene in hippocampal anxiety. ${ }^{32}$ Guo et $\mathrm{al}^{6}$ evaluated pain sensitivity and negative emotional behavior in KCNIP3 -/- rats. It was confirmed that KCNIP3 -/- rats showed higher pain sensitivity, higher anxiety levels and aggravated depression-like behavior than wild-type rats. In addition, the RNA-Seq transcriptional profiling of the forebrain cortex of wild-type and KCNIP3 -/- rats were compared, and the expression of genes involved in dopamine transmission, such as NR4A2, was up-regulated.

The rs3769340 gene polymorphism was associated with weight loss in patients with MDD.

Studies have shown that NR4A2 is involved in steroid production, lipogenesis, and energy metabolism. ${ }^{33,34}$ Amoasii et $\mathrm{al}^{35}$ reported that Mediator 13 inhibits the expression of glucose uptake and metabolism-related genes in skeletal muscle by inhibiting the nuclear receptor NURR1 and MEF2 transcription factors. These findings shed light on the fundamental molecular mechanisms by which skeletal muscle regulates glucose metabolism and lipid accumulation in the liver.

The rs12803 gene polymorphism was associated with insight in patients with MDD. Gerretsen et $\mathrm{al}^{36}$ revealed that impaired insight of delusions was positively associated with the severity of depressive disorder with psychotic characteristics at baseline and that impaired selfawareness of delusions appeared to be an independent predictor of remission of depressive disorder with psychotic characteristics during acute treatment. Another study ${ }^{37}$ reported that more severe anxiety symptoms and previous hospitalizations for MDD were associated with greater insight into illness at admission. Reduction of retardation symptoms during treatment was associated with greater improvement in insight prior to discharge. Patients who were sicker at admission and those who showed more improvement in psychomotor retardation, had the greatest improvement in insight. Ekinci et $\mathrm{al}^{38}$ attempted to compare the cognitive and clinical insights of schizophrenia patients with and without a comorbid depression. They 
found that participants in the depressive group scored significantly higher on self-reflectiveness and the reflectiveness-certainty index than those in the non-depressed group. There have been no studies linking NR4A2 to insight into MDD. Therefore, it is necessary to study the role of NR4A2 in the insight of patients with MDD, and perhaps further studies on NR4A2 and schizophrenia and insight can provide us with ideas for the research on MDD.

In our study, rs3769340 genotype was associated with antidepressant efficacy in patients $(\chi 2=4.123, P=0.042)$, suggesting that different NR4A2 loci may be associated with different therapeutic mechanisms. Thus, the results of our study have certain guiding significance for the development of new antidepressant drugs and individualized treatment strategies. Ibi et $\mathrm{al}^{39}$ investigated the effect of social isolation (SI) on neurogenesis associated with memory and emotion-related behaviors in the dentate gyrus (DG) of the hippocampus. Repeated use of fluoxetine can prevent SI-induced survival damage to newly dividing cells and improve spatial memory impairment and some aggressive behavior in SI mice. In addition, they investigated the changes in gene expression in the DG of SI mice by using DNA microarray and real-time PCR and found that SI reduced the expression of Nurr1 and Npas4 genes related to development. Breuillaud et $\mathrm{al}^{40}$ revealed that mice lacking cyclic adenosine effector elder-binding protein (CREB) regulated transcriptional coactivator 1 (CRTC1) exhibited a depression-like phenotype and a reduced antidepressant response to the selective serotonin reuptake inhibitor fluoxetine. Breuillaud et al ${ }^{40}$ similarly show that $\mathrm{Crtc1}(-/-)$ mice are resistant to the antidepressant effect of chronic desipramine in a behavioral despair paradigm. Supporting the blunted response to this tricyclic antidepressant, we found that desipramine does not significantly increase the expression of BDNF and NR4A2 in the hippocampus and prefrontal cortex of Crtc1(-/-) mice. Although the rs3769340 genotype was associated with the efficacy of antidepressants $(P=0.042)$, it was not significant. Therefore, it is necessary to further expand the sample size to verify the accuracy of the results.

This study has some limitations. First, a small percentage of patients had rare genotypes, so a larger sample size was needed for analysis. Secondly, in this study, the proportion of patients who were able to receive at least 6 weeks of treatment as prescribed by the doctor was too low, and the treatment duration may not be long enough, which may lead to the deviation of the study results. Therefore, we should develop strategies to improve patient compliance to cure the disease. Finally, this study only analyzed gene level, not RNA and protein expression, and could not directly and systematically describe the relationship between depressive symptoms and NR4A2.

In general, these findings demonstrate the significant association between NR4A2 gene polymorphisms and retardation: psychomotor, somatic general symptoms (gastrointestinal), somatic anxiety symptoms, weight loss, and insight in patients with MDD. This suggests that phenotypic studies may be more suitable for molecular genetic studies of depression disorders, suggesting that we can further collect patients with different diagnoses of mental disorders in future studies, and further classify patients according to phenotypes, so as to study the genetic mechanism of a certain phenotype. NR4A2 gene polymorphism may be a predictor of antidepressant efficacy. It is expected that this finding will provide a theoretical basis for further research on the relationship between NR4A2 and depressive disorders.

In the meantime, we will continue to conduct casual molecular studies to examine whether these three SNPs are associated with differences in NR4A2 expression in humans and how NR4A2 is associated with antidepressant efficacy.

\section{Acknowledgments}

This study was supported by National Natural Science Foundation of China (81971601), the National Natural Science Youth Fund Project (81701345), National key research and development program of China (2016YFC1307103), Natural Science Foundation of Shanxi Province for Youths (201801D221418), Research Project Supported by Shanxi Scholarship Council of China (HGKY2019098), 136 Medical Rejuvenation Project of Shanxi Province, Program of the Youth Sanjin Scholars, and Program for the Outstanding Innovative Teams of Higher Learning Institutions of Shanxi.

\section{Author Contributions}

All authors made a significant contribution to the work reported, whether that is in the conception, study design, execution, acquisition of data, analysis and interpretation, or in all these areas; took part in drafting, revising or critically reviewing the article; gave final approval of the version to be published; have agreed on the journal to which the article has been submitted; and agree to be accountable for all aspects of the work. 


\section{Disclosure}

The authors report no conflicts of interest for this work.

\section{References}

1. Kendler KS, Gatz M, Gardner CO, Pedersen NL. A Swedish national twin study of lifetime major depression. Am J Psychiatry. 2006;163 (1):109-114. doi:10.1176/appi.ajp.163.1.109

2. Daily E, Chenu F, Renard CE, et al. Dopamine, depression and antidepressants. Fundam Clin Pharmacol. 2004;18:601-607.

3. Cools R, Froböse M, Aarts E, Hofmans L. Dopamine and the motivation of cognitive control. Handb Clin Neurol. 2019;163:123-143. doi:10.1016/B978-0-12-804281-6.00007-0

4. Belujon P. Grace AA2. Dopamine system dysregulation in major depressive disorders. Int $J$ Neuropsychopharmacol. 2017;20 (12):1036-1046. doi:10.1093/ijnp/pyx056

5. Park TY, Jang Y, Kim W, et al. Chloroquine modulates inflammatory autoimmune responses through Nurr1 in autoimmune diseases. Sci Rep. 2019;9(1):15559. doi:10.1038/s41598-019-52085-w

6. Guo YP, Zhi YR, Liu TT, Wang Y, Zhang Y. Global gene knockout of Kcnip3 enhances pain sensitivity and exacerbates negative emotions in rats. Front Mol Neurosci. 2019;12:5. doi:10.3389/fnmol.2019.0 0005

7. Jakaria M, Haque ME, Cho DY, Azam S, Kim IS, Choi DK. Molecular insights into NR4A2(Nurr1): an emerging target for neuroprotective therapy against neuroinflammation and neuronal cell death. Mol Neurobiol. 2019;56(8):5799-5814. doi:10.1007/s12035019-1487-4

8. Rojas P, Joodmardi E, Perlmann T, Ogren SO. Rapid increase of Nurr1 mRNA expression in limbic and cortical brain structures related to coping with depression-like behavior in mice. $J$ Neurosci Res. 2010;88(10):2284-2293. doi:10.1002/jnr.22377

9. Kerman IA, Bernard R, Bunney WE, et al. Evidence for transcriptional factor dysregulation in the dorsal raphe nucleus of patients with major depressive disorder. Front Neurosci. 2012;6:135. doi:10.3389/ fnins.2012.00135

10. Zetterstrom RH, Solomin L, Jansson L, Hoffer BJ, Olson L. Perlmann Dopamine neuron agenesis in Nurr1-deficient mice. Science. 1997;276:248-250.

11. Eells JB, Lipska BK, Yeung SK, Misler JA. Nikodem Nurr1-null heterozygous mice have reduced mesolimbic and mesocortical dopamine levels and increased stress-induced locomotor activity. Behav Brain Res. 2002;136:267-275.

12. Ojeda V, Fuentealba JA, Galleguillos D, Andres ME. Rapid increase of Nurr1 expression in the substantia nigra after 6-hydroxydopamine lesion in the striatum of the rat. Neurosci Res (NY). 2003;73:686-697.

13. Zetterstrom RH, Williams R, Perlmann T, Olson L. Cellular expression of the immediate early transcription factors Nurrl and NGFI-B suggests a gene regulatory role in several brain regions including the nigrostriatal dopamine system. Brain Res Mol Brain Res. 1996;41:111-120.

14. Ruano D, Macedo A, Dourado A, et al. NR4A2 and schizophrenia: lack of association in a Portuguese/Brazilian study. Am J Med Genet B Neuropsychiatr Genet. 2004;128B(1):41-45.

15. Liu H, Fu Y, Ren J, et al. Association between NR4A2 genetic variation and schizophrenia: a comprehensive systematic review and meta-analysis. Neurosci Lett. 2015;598:85-90. doi:10.1016/j. neulet.2015.05.018

16. Chen YH, Tsai MT, Shaw CK, Chen CH. Mutation analysis of the human NR4A2 gene, an essential gene for midbrain dopaminergic neurogenesis, in schizophrenic patients. $A m$ J Med Genet. 2001;105:753-757.

17. Ruano D, Macedo A, Dourado A, et al. NR4A2 and schizophrenia: lack of association in a Portuguese/Brazilian study. Am J Med Genet B Neuropsychiatr Genet. 2004;128B:41-45.
18. Ng MY, Levinson DF, Faraone SV, et al. Meta-analysis of 32 genome-wide linkage studies of schizophrenia. Mol Psychiatry. 2009; 14:774-785.

19. Rojas P, Joodmardi E, Hong Y, Perlmann T, Ogren SO. Adult mice with reduced Nurr1 expression: an animal model for schizophrenia. Mol Psychiatry. 2007;12:756-766.

20. Buervenich S, Carmine A, Arvidsson M, et al. NURR1 mutations in cases of schizophrenia and manic-depressive disorder. Am J Med Genet. 2000;96(6):808-813.

21. Diagnostic and Statistical Manual of Mental Disorders. 4. Washington, DC: American Psychiatric Association; 2000.

22. Widlocher DJ. Psychomotor retardation: clinical, theoretical, and psychometric aspects. Psychiatr Clin North Am. 1983;6(1):27-40.

23. Buyukdura JS, McClintock SM, Croarkin PE. Psychomotor retardation in depression: biological underpinnings, measurement, and treatment. Prog Neuropsychopharmacol Biol Psychiatry. 2011;35 (2):395-409. doi:10.1016/j.pnpbp.2010.10.019

24. Savitz J, Frank MB, Victor T, et al. Inflammation and neurological disease-related genes are differentially expressed in depressed patients with mood disorders and correlate with morphometric and functional imaging abnormalities. Brain Behav Immun. 2013;31:161-171.

25. Saczynski JS, Beiser A, Seshadri S, Auerbach S, Wolf PA, Au R. Depressive symptoms and risk of dementia: the Framingham Heart Study. Neurology. 2010;75:35-41.

26. Leonard BE. Inflammation, depression and dementia: are they connected? Neurochem Res. 2007;32:1749-1756.

27. Powell N, Walker MM, Talley NJ. The mucosal immune system: master regulator of bidirectional gut-brain communications. Nat Rev Gastroenterol Hepatol. 2017;14:143-159.

28. Moulton CD, Pavlidis P, Norton C, et al. Depressive symptoms in inflammatory bowel disease: an extraintestinal manifestation of inflammation? Clin Exp Immunol. 2019;197(3):308-318. doi:10.1111/cei.13276

29. Herman A. Probiotics supplementation in prophylaxis and treatment of depressive and anxiety disorders - a review of current research. Psychiatr Pol. 2019;53(2):459-473. doi:10.12740/PP/92392

30. Han Y-F, Cao G-W. Role of nuclear receptor NR4A2 in gastro-intestinal inflammation and cancers. World $J$ Gastroenterol. 2012;18(47):6865-6873. doi:10.3748/wjg.v18.i47.6865

31. John W, Tiller G. Depression and anxiety. Med J Aust. 2013;199(S6): S28-31.

32. Le-niculescu H, Balaraman Y, Patel SD, et al. Convergent functional genomics of anxiety disorders: translational identification of genes, biomarkers, pathways and mechanisms. Transl Psychiatry. 2011;1(5):e9.

33. van Tiel CM, de Vries CJM. NR4All in the vessel wall. J Steroid Biochem Mol Biol. 2011;130(3-5):186-193.

34. Zhao Y, Bruemmer D. NR4A orphan nuclear receptors: transcriptional regulators of gene expression in metabolism and vascular biology. Arterioscler Thromb Vasc Biol. 2010;30:1535-1541.

35. Amoasii L, Sanchez-Ortiz E, Fujikawa T, Elmquist JK, Bassel-Duby R, Olson EN. NURR1 activation in skeletal muscle controls systemic energy homeostasis. Proc Natl Acad Sci U S A. 2019;116 (23):11299-11308. doi:10.1073/pnas.1902490116

36. Gerretsen P, Flint AJ, Whyte EM, Rothschild AJ, Meyers BS, Mulsant BH. Impaired Insight into delusions predicts treatment outcome during a randomized controlled trial for psychotic depression (STOP-PD Study). $J$ Clin Psychiatry. 2015;76(4):427-433. doi:10.4088/JCP.14m09003

37. Hongbo H, Chang Q, Yarong M. The association of insight and change in insight with clinical symptoms in depressed inpatients. Shanghai Arch Psychiatry. 2018;30(2):110-118. doi:10.11919/j. issn.1002-0829.217149

38. Ekinci O, Ugurlu GK, Albayrak Y, Arslan M, Caykoylu A. The relationship between cognitive insight, clinical insight, and depression in patients with schizophrenia. Compr Psychiatry. 2012;53 (2):195-200. doi:10.1016/j.comppsych.2011.02.010 
39. Ibi D, Takuma K, Koike H, et al. Social isolation rearing-induced impairment of the hippocampal neurogenesis is associated with deficits in spatial memory and emotion-related behaviors in juvenile mice. J Neurochem. 2008;105(3):921-932. doi:10.1111/j.14714159.2007.05207.x
40. Breuillaud L, Rossetti C, Meylan EM, et al. Deletion of CREB-regulated transcription coactivator 1 induces pathological aggression, depression-related behaviors, and neuroplasticity genes dysregulation in mice. Biol Psychiatry. 2012;72:528-536.

\section{Publish your work in this journal}

Neuropsychiatric Disease and Treatment is an international, peerreviewed journal of clinical therapeutics and pharmacology focusing on concise rapid reporting of clinical or pre-clinical studies on a range of neuropsychiatric and neurological disorders. This journal is indexed on PubMed Central, the 'PsycINFO' database and CAS, and is the official journal of The International Neuropsychiatric Association (INA). The manuscript management system is completely online and includes a very quick and fair peer-review system, which is all easy to use. Visit http://www.dovepress.com/testimonials.php to read real quotes from published authors. 